\title{
Os movimentos sociais como campo de pesquisa nas ciências humanas
}

\section{Leonilde Servolo de Medeiros*}

Resumo: Este artigo objetiva mapear alguns dos temas envolvidos na pesquisa sobre movimentos sociais. Partindo de questões suscitadas pela dicotomia entre novos e velhos movimentos sociais, que se difundiu nos anos 1980, elenca alguns temas centrais para o estudo da formação dos movimentos e sua relação com a sociedade e o Estado. Assim, apresenta alguns apontamentos sobre a formação do ator coletivo, contexto de mobilização e constituição de demandas, o espaço público e as interações entre movimentos sociais e Estado, transnacionalização dos movimentos sociais e suas implicações na discussão de repertórios de ação coletiva.

Palavras-chave: Movimentos sociais; Ação coletiva; Espaço público.

\begin{abstract}
This article intends to give an overview of some issues involved in the research of social movements based on the current literature in the Social Sciences. Having as a starting point questions raised by the dichotomy between "old" and "new" social movements, a widespread trend in the late seventies, this article focus on some central themes that have being object of attention by theorists and researchers. Therefore, it approaches questions like the process of collective actor formation, mobilizations and construction of demands, public space, interactions between the people who are mobilized and the State, and the process of transnacionalization and its effects on the analysis of collective action.
\end{abstract}

Keywords: Social movements; Collective action; Public space.

\section{INTRODUÇÃO}

Os eventos que ficaram conhecidos como "Primavera Árabe", os protestos públicos em vários países europeus contra os efeitos da crise econômica, a visibilidade das organizações indígenas da América Latina por meio de ações contra construções de grandes obras como hidrelétricas e estradas, o occupy Wall Street, entre outros acontecimentos recentes, mostram uma enorme capacidade de mobilização dos mais diversificados segmentos da população, em torno de temas também bastante diferenciados: afirmação de identidades étnicas, reconhecimento e busca de direitos, crítica aos níveis crescentes de desemprego e a determinadas formas de organização da vida social e política, defesa de modos de vida tradicionais etc. Lado a lado com esses acontecimentos, continuamos a assistir lutas por melhores salários e condições de trabalho, indicando que este tema permanece na pauta, como motivador de demandas e produtor de conflitos. Chama ainda a atenção o fato de que crescem as articulações entre organizações e grupos distintos em

\footnotetext{
* Professora do Programa de Pós-Graduação de Ciências Sociais em Desenvolvimento, Agricultura e Sociedade da Universidade Federal Rural do Rio de Janeiro. Bolsista do CNPq e da Faperj (Programa Cientistas do Nosso Estado). As citações presentes neste artigo, derivadas de literatura em inglês ou francês, são traduções dos textos utilizados feitas por mim.
} 
países de todo o globo, como nos mostram acontecimentos como os Fóruns Sociais Mundiais, a Via Campesina, a Cúpula dos Povos na Rio+20.

Enfim, somos testemunhas de uma miríade de fatos que mantêm na ordem do dia o debate sobre a relevância dos movimentos sociais e nos obrigam a atualizar esforços teóricos e metodológicos para melhor compreender esses processos complexos, que se evidenciam em suas fases expressivas, mas que, certamente, demandam um olhar mais criterioso, capaz de ir além do que Alberto Melucci chamou de "miopia do visível", de forma a perceber redes menos perceptíveis e assinalar continuidades, rupturas, ressignificações. ${ }^{1}$

Para tornar o panorama ainda mais complexo, se até há bem pouco tempo (anos 1990) as formas de aparecer das demandas seguiam determinados padrões que compunham o que Tilly ${ }^{2}$ chamou de "repertório de ação coletiva", vem crescendo o uso de instrumentos capazes de dinamizar a comunicação entre pessoas e produzir novas formas de ação. Com efeito, a internet e a construção de redes sociais virtuais (e-mails, Facebook, Twitter) tornaram-se parte e/ou instrumento das mobilizações coletivas: não só somos cada vez mais instados a assinar petições e manifestos que nos chegam por e-mail, como também percebemos a incrível potencialidade dos recursos virtuais para difundir causas e produzir adesões, numa rapidez antes impensável. Esses instrumentos vêm se mostrando capazes não só de gerar protestos presenciais (por exemplo, na forma tradicional de atos públicos), como também mobilizações on line, na forma de campanhas, que podem originar ações de protesto coletivo de caráter presencial. Em todas essas situações, o que chama a atenção é a velocidade com que a informação circula e sua capacidade de atingir cada vez mais pessoas, além de demonstrar seu grande potencial de afetar tanto o cotidiano, quanto a vida econômica, social e política.

Esses eventos nos colocam frente a novas e antigas questões sobre as razões e as condições que levam as pessoas a se mobilizar, de que forma pautas são constituídas, como se formam atores coletivos, quais as implicações dos processos, cada vez mais recorrentes, de transnacionalização dos movimentos sociais. Se, como aponta Cefaï, é fundamental entender "o que mantém juntas as pessoas, ao que elas se prendem e o que as faz se prenderem", 3 a realidade está nos mostrando que as formas de se estar junto podem variar desde a concentração numa praça até a possibilidade de conseguir, em um dia, milhares de assinaturas para um abaixo-assinado. Evidentemente, pode-se argumentar que estamos frente a formas e níveis de engajamento bastante diferenciados, por vezes pontuais e provisórios, mas o fato é que se trata de iniciativas plurais de mobilização, em busca de algum tipo de eficácia política.

Nesse quadro mais geral, permanece a discussão sobre que tipo de fenômeno pode ser classificado como movimento social ou se a noção de política de conflito, mais

\footnotetext{
${ }^{1}$ MELUCCl, Alberto. A Invenção do presente. Movimentos sociais nas sociedades complexas. Petrópolis: Vozes, 2001.

2 TILLY, Charles. From mobilization to revolution. Reading, Massachusetts: Addison-Wesley, 1978; TILLY, Charles. Regimes and repertoires. Chicago: Chicago Press, 2006.

${ }^{3}$ CEFAï, Daniel. Como nos mobilizamos. In: Dilemas - Revista de Estudos de Conflito e Controle Social, IFCS/UFRJ, vol. 2, n. 4, abril-jun., 2009, p. 25.
} 
abrangente, não seria mais adequada para dar conta das formas mais organizadas de expressão da conflituosidade no mundo contemporâneo. Neste artigo, não tenho a intenção de enfrentar esse conjunto de questões. Embora relevantes, elas ultrapassam de longe o que pode ser tratado num número limitado de páginas. Vou procurar trazer algumas reflexões preliminares, fundadas quer em experiência de pesquisa sobre os movimentos sociais rurais no Brasil, quer inspiradas em textos de alguns autores considerados relevantes para o avanço da discussão, procurando, em cada um dos tópicos que se seguem, elencar alguns argumentos em torno de alguns temas centrais para entender as formas de mobilização contemporâneas. Não há qualquer intenção de dar conta de todas as questões em jogo, mas apenas de chamar a atenção para alguns aspectos os quais um pesquisador do tema acaba tendo que enfrentar ao longo do processo de pesquisa empírica.

\section{"VELHOS" E "NOVOS" MOVIMENTOS SOCIAIS: QUEM SÃO OS ATORES?}

Como aponta Jeffrey Alexander, na história da teoria social, "os movimentos sociais foram identificados segundo o modelo dos movimentos revolucionários, entendidos como mobilizações de massa que visam apossar-se de um Estado antagônico". ${ }^{4}$ Sob essa perspectiva, em especial o pensamento marxista, nas suas diferentes correntes, fez do movimento operário a expressão por excelência do processo de mudança social e política. Por um longo período (desde aproximadamente os anos 1830, ou seja, por quase todo o século XIX, até pelo menos os anos 1960), os trabalhadores fabris - e suas expressões organizativas predominantes, o sindicato e o partido - apareceram identificados à ideia de movimento social. No entanto, mudanças importantes se produziram nos anos posteriores, trazendo outros atores e novas questões para a cena política e provocando indagações sobre a abrangência e possibilidades explicativas da categoria "movimentos sociais".

A emergência, nos anos 1960 e 1970 no Ocidente, de uma série de eventos que traziam à tona demandas de diversos segmentos sociais antes politicamente invisibilizados instigou o pensamento sociológico no sentido de entender as diferentes manifestações públicas que ocorriam e que não podiam nem ser traduzidas em termos estritamente classistas, nem como fenômenos de patologia social. As formas tradicionais de mobilização o partido e o sindicato -, embora continuassem presentes na cena política, pareciam estar sendo superadas por outros formatos organizativos e outros atores sociais, protagonistas de novas formas de conflito que emergiam. Os movimentos negros nos Estados Unidos e as lutas das mulheres, ambos exigindo reconhecimento e igualdade de direitos; as lutas de estudantes em diversos pontos do mundo contra determinadas regras hierárquicas da academia; o movimento de contracultura; os movimentos pacifistas e ambientalistas, para mencionar apenas os mais citados na bibliografia especializada, mostraram a necessidade de instrumentos teóricos capazes de dar conta dessa nova configuração. Os conflitos sociais

\footnotetext{
${ }^{4}$ ALEXANDER. Jeffrey. Ação coletiva, cultura e sociedade civil: secularização, atualização, inversão, revisão e deslocamento do modelo clássico dos movimentos sociais. In Revista Brasileira de Ciências Sociais, vol. 13, 37, Junho/1998, p. 5.
} 
emergentes traziam questões (relações de gênero e de geração, reconhecimento de identidades étnicas, demanda por acesso amplo a direitos sociais e políticos, recusa à guerra, defesa da preservação ambiental etc.) que envolviam outras esferas da vida que não aquelas ligadas diretamente à produção e ao trabalho e não podiam ser traduzidas nem explicadas em termos estritamente classistas.

Data dessa época a utilização da expressão "novos movimentos sociais", que reflete esforços teóricos para dar conta da emergência desses novos personagens e questões. Melucci, um dos autores que teve um importante papel ao cunhar essa categoria de análise, ${ }^{5}$ chama a atenção para o fato de que

os movimentos juvenis, feministas, ecológicos, étnico-nacionais, pacifistas não têm somente colocado em cena atores conflituais, formas de ação e problemas estranhos à tradição de lutas do capitalismo industrial; eles têm colocado também, no primeiro plano, a inadequação das formas tradicionais de representação política para acolher de maneira eficaz as questões emergentes ${ }^{6}$.

Na sua percepção, tornava-se difícil a delimitação de um ator coletivo e era necessária uma inversão epistemológica, implicando um investimento no sentido de separar, no plano metodológico, a análise de uma condição social e o estudo da ação coletiva. Para o autor, tratava-se de inverter os termos do problema:

A ação não se deduz pela condição social. É necessário, ao contrário, mudar completamente o procedimento: isto é, identificar, a nível do sistema, os problemas que estão no centro dos conflitos sociais, os campos sobre os quais se joga o confronto para o controle de recursos decisivos". ${ }^{7}$

Os movimentos sociais que emergiram a partir dos 1960 dão conta, segundo ele, de um novo tempo: o de uma sociedade descentrada, onde há atores múltiplos, uma pluralidade de planos e instrumentos de transformação social e uma irredutibilidade em relação às suas diferenças.

Dessa perspectiva, a preocupação se desloca para o próprio processo de constituição do ator coletivo. Como ele não é prévio e não está dado na estrutura social, sua formação é a questão a ser desvendada. Assim, o autor se distancia do que, no senso comum e empiricamente, é chamado de "movimento social", ente dotado de uma dimensão substantiva, e encaminha suas indagações para os processos sociais complexos que formam essa unidade: ela se torna ponto de chegada e não de partida para a análise.

\footnotetext{
${ }^{5}$ Entre os autores que contribuíram de forma decisiva para fundá-la, além de Alberto Melucci, estão Alain Touraine e Claus Offe. Ver, entre outros, TOURAINE, Alain. Le voix et le regard. Paris: Seuil, 1978; . Anais do seminário O retorno do ator. São Paulo: USP/Faculdade de Educação, 1989; Poderemos viver juntos? Iguais e diferentes. Petrópolis: Vozes, 1999; e OFFE, Claus. Los nuevos movimientos sociales cuestionan los limites de la política institucional. In: Editorial Sistema, 1996.

${ }^{6}$ MELUCCl, op. cit., p. 95.

${ }^{7}$ Ibidem, p. 100.
} 
Há aí uma inversão metodológica importante, que move a reflexão para os processos menos visíveis, descritos como "redes submersas de grupos, de pontos de encontro, de circuitos de solidariedade que diferem profundamente da imagem do ator político organizado", com reflexos profundos nas formas de representação política. ${ }^{8}$ Para ele, é necessário que nos afastemos da "miopia do visível", correspondente a uma aproximação analítica que

concentra toda a atenção sobre os aspectos mensuráveis da ação coletiva, isto é, a relação com os sistemas políticos e os efeitos sobre as políticas, ignorando, ao contrário, a produção de códigos culturais que constitui a principal atividade de redes submersas do movimento. ${ }^{9}$

Há alguns aspectos dignos de nota nessa reflexão. Entre eles, destacamos as pistas abertas com o deslocamento da centralidade explicativa para a cultura e para redes de solidariedade, que são a marca das teorias que buscam explicar os chamados "novos movimentos sociais", preocupadas que estão em identificar as transformações nas esferas do cotidiano. Trata-se de problematizar as condições em que emerge o sujeito coletivo, uma vez que este não está dado, não é prévio, mas se forma no próprio processo do conflito, constituindo identidades essencialmente provisórias e relacionais. Como tentaremos mostrar neste artigo, autores de diferentes inserções teóricas acabaram convergindo, ao longo das últimas décadas, para uma revalorização das dimensões culturais presentes na ação coletiva, alargando assim a esfera do que se pode considerar como o "político".

No entanto, estas mesmas pistas metodológicas oferecem a possibilidade de releituras dos conflitos que marcaram a sociedade industrial. Contribuição significativa nessa direção nos é oferecida por Craig Calhoun. Chamando a atenção para o fato de que a oposição entre "novos" e "velhos" movimentos sociais aparece na literatura como uma espécie de sucessão histórica, esse autor propõe que se descarte esse entendimento simplificador dos processos sociais e alerta para o fato de que as ideias que estão no centro da teoria dos chamados "novos" movimentos sociais "oferecem lentes úteis para olhar para os movimentos do século XIX" ${ }^{10}$ Essa inflexão na abordagem, de cuja fertilidade o autor fornece abundantes exemplos em seu artigo, coloca em questão a própria narrativa dominante sobre a modernidade e a relação entre esta e a emergência dos movimentos sociais. ${ }^{11}$

Calhoun, apropriando-se das questões metodológicas postas por esse novo olhar, reindaga o passado e acaba mostrando a possibilidade de iluminar aspectos dos conflitos sociais do século XIX, para os quais a literatura sociológica e da Ciência Política deu pouca

\footnotetext{
8 Ibidem, p. 97.

9 Ibidem, p. 26.

10 CALHOUN, Craig. "New social movements" of the early nineteenth century. In Mark Traugott (ed). Repertories \& cycles of collective action. Durham e London: Duke University Press, 1995, p. 180.

${ }^{11}$ Para diversos autores, entre eles Touraine e Melucci, a emergência dos chamados "novos" movimentos sociais corresponde a um novo padrão societal (sociedade pós-industrial, sociedade descentrada etc). Ver MELUCCl, op cit.; . Chalenging codes. Collective action in the information age. Cambridge: Cambridge University Press, 1996; e TOURAINE, Poderemos viver juntos?, op. cit.
} 
importância, contribuindo, assim, para sua invisibilização. Argumenta, entre outras coisas, que é possível perceber na análise desse período uma política de identidades, a presença de utopias comunitárias, o uso de ação direta não convencional, a constituição de redes que entrecruzavam movimentos específicos, a emergência de uma série de novas questões no espaço público etc., temas típicos do debate sobre os chamados "novos" movimentos sociais. $^{12}$

Há que se ressaltar ainda que, se o movimento operário perdeu sua centralidade em alguns países, em especial nos europeus, onde esteve intimamente ligado a um conjunto de transformações sociais e políticas significativas ao longo dos séculos XIX e XX, é necessário considerar tempos e contextos históricos diversificados. Ou seja, qualquer modelo deve ser visto com muita cautela e tem que ser apropriado considerando-se as condições teóricas e também históricas em que foi gerado. Se olharmos, por exemplo, para a história recente do Brasil, vemos que o que foi chamado entre nós de "novos movimentos sociais" (e que se constituíram em força condutora no processo de redemocratização do país) combinou com o aparecimento do que ficou conhecido como "novo sindicalismo" e com a constituição de experiências políticas inovadoras que se definiram como classistas, como é o caso da formação do Partido dos Trabalhadores, no início dos anos 1980. Da mesma forma, as ocupações de terra que passaram a ocorrer com intensidade desde o final dos anos 1970, reafirmaram a questão fundiária de uma maneira fortemente classista, revigorando a oposição entre as diversas formas de trabalho no campo e o "latifúndio", termo que recobria tanto uma determinada forma de apropriação da terra, como relações de exploração e opressão. ${ }^{13}$ Se essas ações não encontraram no sindicato seu canal de expressão, não deixa de ser significativo que os sindicatos também tenham empunhado a bandeira da reforma agrária e tenham sido atores fundamentais para que o debate em torno das transformações fundiárias ganhasse destaque na Aliança Democrática e no início da Nova República. ${ }^{14}$ Finalmente, hoje, não só no Brasil como na América Latina, não é difícil perceber o quanto segmentos que até há pouco pareciam secundários ou inexpressivos ganharam força política no cruzamento de identidades étnicas e classistas. É o caso, por exemplo, da Bolívia ou do Equador, onde a afirmação de identidades indígenas seculares se mescla com a construção de uma identidade camponesa e um discurso classista.

Estamos frente a uma diversidade de atores que colocam diferentes ordens de questões e vão constituindo uma arena pública, entendida como lugar de produção,

\footnotetext{
${ }^{12}$ CALHOUN, op. cit.

${ }^{13}$ NOVAES, Regina. De corpo e alma. Rio de Janeiro: Graphia, 1997.

${ }^{14}$ É das mobilizações para ocupação de terras que surge o Movimento dos Trabalhadores Rurais sem Terra (MST), que propõe uma forma de organização menos hierárquica e presa às normas legais que o sindicato, mas que, em sua origem, é bastante ligado às "oposições sindicais", movimento amplo que se opunha não aos sindicatos, mas a uma determinada forma de organização sindical e, principalmente, a um padrão de práticas que conformavam um sindicato "acomodado", pouco afeito às mobilizações coletivas. No que se refere ao sindicalismo de trabalhadores rurais, chama ainda a atenção sua capacidade de incorporar questões relacionadas aos temas de gênero e de juventude, que muitas vezes emergiram dentro dos próprios sindicatos.
} 
circulação e troca de argumentos. ${ }^{15}$ Trata-se de argumentos de vários tipos, que vão, ao mesmo tempo em que se configuram, produzir os atores políticos, na medida em que se efetiva seu reconhecimento e em que suas questões passam a compor a pauta do que é aceito como passível de discussão. Nesse processo, atores e temas se mesclam, não nos autorizando a simplesmente deixar de lado argumentos que incorporam uma linguagem classista. Sem dúvida, são muitas as ressignificações e traduções, mas o enquadramento de classe não desaparece totalmente.

Mesmo se considerarmos a literatura europeia, verificamos que a questão da classe não foi de todo abandonada, embora tenha perdido a centralidade explicativa. Nos anos 1970 e 1980, o próprio marxismo se renovou e passou a pensar classes e lutas de classes com base em outros parâmetros, que não somente os estruturais. Para tanto, foi fundamental tanto a divulgação do pensamento gramsciano, que reflete sobre as condições de formação de uma vontade coletiva e sobre as condições de produção da hegemonia (entendida como direção moral e intelectual de um grupo sobre outros), quanto a contribuição de Thompson que, no seu monumental estudo sobre a formação da classe operária inglesa, entende classe não como categoria prévia, mas como processo, grupo social que está presente na sua própria constituição, no sentido de que é um agente ativo da história. ${ }^{16}$ Na sua perspectiva, classe é uma categoria histórica,

\begin{abstract}
derivada da observação do processo social ao largo do tempo. Sabemos que há classes porque as pessoas se comportaram repetidamente de modo classista; estes acontecimentos históricos descobrem regularidades nas respostas a situações similares, e em um momento dado (a formação "madura" de classe), observamos a criação de instituições e de uma cultura com notações de classe, que admitem comparações transnacionais. ${ }^{17}$
\end{abstract}

No campo das Ciências Sociais, o tema sofreu inflexões interessantes, que permitiram novas leituras sobre as possibilidades de atualizar a categoria classe e suas implicações, buscando percebê-la não como essência, mas como construção social, que se faz a partir de disputas políticas e simbólicas. Przeworski, por exemplo, em texto publicado originalmente em meados dos anos 1980, afirma que "as classes não são determinadas unicamente por quaisquer posições objetivas porque constituem efeitos de lutas, e essas lutas não são determinadas exclusivamente pelas relações de produção". ${ }^{18}$ De acordo com esse autor, as classes também são organizadas e desorganizadas em função de lutas contínuas.

\footnotetext{
${ }^{15}$ CEFAï, Daniel. Como uma associação nasce para o público: vínculos locais e arena pública em torno da associação La Bellevilleueuse em Paris. In: et al. (orgs.) Arenas públicas: por uma etnografia da vida associativa. Niterói: Editora da UFF, 2011, p. 90.

${ }^{16}$ THOMPSON, Edward P. A formação da classe operária na Inglaterra. Rio de Janeiro: Paz e Terra, 1987. Vol. 1: A árvore da liberdade; . A formação da classe operária na Inglaterra. Rio de Janeiro: Paz e Terra, Vol. 2: A maldição de Adão; . A formação da classe operária na Inglaterra. Rio de Janeiro: Paz e Terra. Vol. 3: A força dos trabalhadores.

17 __ La sociedad inglesa del siglo XVIII: ¿ilucha de classes sin classes?. In Edward Thompson. Tradición, Revuelta y Consciencia de Classe. Barcelona: Ed. Critica, 1979, p. 34.

${ }^{18}$ PRZEWORSKI, Adam. A organização do proletariado em classe. In: São Paulo: Companhia das Letras, 1989, p. 86. Capitalismo e Social Democracia.
} 
Partidos que se definem como representantes dos interesses de várias classes e partidos que se pretendem representantes do interesse geral, sindicatos, jornais, escolas, burocracia oficial, associações, "todos participam do processo de formação de classes no decorrer de lutas que dizem respeito fundamentalmente à própria divisão da sociedade [...]. A luta ideológica é uma luta a respeito de classes antes de ser uma luta entre classes". ${ }^{19}$ Para ele, as lutas econômicas também não existem em si, são sempre moldadas por lutas políticas e ideológicas: "O próprio direito de organizar-se é um efeito de lutas que, por sua vez, estabelecem a forma de organização da classe". ${ }^{20}$

Mais crítico da tradição marxista, também Bourdieu ressemantiza o conceito de classe. Classe, para ele, é o conjunto dos agentes que ocupam posição semelhante e que, colocados em condições semelhantes e sujeitos a condicionamentos semelhantes, tem, com toda probabilidade, atitudes e interesses semelhantes, logo, práticas e tomadas de posição similares. Pelo lugar que as pessoas ocupam no espaço social, pode-se compreender a lógica de suas práticas e determinar, entre outras coisas, como elas vão classificar e se classificar e, se for o caso, se pensar como membros de uma "classe". ${ }^{21}$ A classe tem existência teórica, é uma classificação que permite explicar e prever as práticas e propriedades das coisas classificadas, mas não tem necessariamente existência real. O que existe é um espaço de relações. A probabilidade de reunir realmente ou nominalmente um conjunto de agentes é tanto maior quanto maior é sua proximidade no espaço social e quanto mais homogênea é a classe construída a que eles pertencem.

Como Thompson, Bourdieu afirma que as classes estão por se fazer. E isso se dá mediante um trabalho político que possui tanto mais possibilidades de ser bem sucedido quanto mais se munir de uma teoria bem fundada na realidade, logo, mais capaz de exercer um efeito de teoria, isto é, de impor uma visão das divisões. ${ }^{22}$ Refere-se a isso como "poder simbólico", poder de fazer grupos, chamando a atenção para a luta por uma imposição de uma visão de mundo legítima, na qual a própria ciência está envolvida e os agentes têm poder em função de seu capital. Isso é essencial no fazer das classes e, para tanto, é preciso capital simbólico e eficácia simbólica, pois a descrição só faz as coisas na medida em que a elas é adequada. ${ }^{23} \mathrm{O}$ trabalho de categorização, explicitação e classificação faz-se sem cessar no mundo social, mas a passagem do implícito ao explícito não é automática. Para Bourdieu,

\footnotetext{
${ }^{19}$ Ibidem, p. 90, grifos do autor.

${ }^{20}$ Ibidem, p. 91.

${ }^{21}$ Espaço social é entendido conjunto de relações de força objetivas impostas a todos os que entrem num determinado campo e irredutíveis às intenções dos agentes individuais ou mesmo às interações diretas entre os agentes. O espaço social é multidimensional, um conjunto aberto de campos relativamente autônomos, mas subordinados quanto ao seu funcionamento e às suas transformações, de modo mais ou menos firme e mais ou menos direto ao campo de produção econômica: no interior de cada um dos subespaços, os ocupantes das posições dominantes e os ocupantes das posições dominadas estão ininterruptamente envolvidos em lutas de diferentes formas (sem por isso se constituírem necessariamente em grupos antagonistas). Ver a respeito, BOURDIEU, Pierre. O poder simbólico. Rio de Janeiro/Lisboa: Bertrand Brasil/Difel, 1990, p. 67.

${ }^{22}$ BOURDIEU, 1990, p. 156

${ }^{23}$ Ibidem, p. 166/167
} 
a classe (ou o povo, ou a nação ou qualquer outra realidade social de outro modo inapreensível) existe se existirem pessoas que possam dizer que elas são a classe, pelo simples fato de falarem publicamente, oficialmente, no lugar dela, e de serem reconhecidas como legitimadas para fazê-lo por pessoas que, desse modo, se reconhecem como membros da classe, do povo, da nação ou de qualquer outra realidade social que uma construção do mundo realista possa inventar e impor. ${ }^{24}$

Como os que ocupam as posições dominadas no espaço social estão também em posições dominadas no campo da produção simbólica, precisam de uma representação permanente, capaz de produzir a representação da continuidade da classe, sempre ameaçada de recair na descontinuidade da existência atomizada ou permanecer nas particularidades das lutas reivindicativas. Tomando como exemplo a classe operária, diz que a sua existência, reconhecida quase que universalmente, assenta na existência de uma "classe operária em representação", quer dizer, em aparelhos políticos e sindicais e portavozes permanentes, interessados em crer que ela existe e em fazê-lo crer tanto àqueles que a ela pertencem como àqueles que a rejeitam. ${ }^{25}$

Assim, as formas de identidade coletiva reconhecidas são o produto de uma longa e lenta elaboração coletiva. Para se legitimar, o grupo tende a um trabalho de naturalização. 0 analista, para não ser iludido pelos efeitos desse trabalho, deve reconstruir o trabalho histórico de que são produto as divisões sociais e a visão social dessas divisões.

Numa perspectiva distinta, mas em diálogo com Bourdieu, Klaus Eder é outro autor que tenta atualizar o conceito de classe. E o faz a partir da análise dos movimentos sociais, chamando a atenção para o fato de que os "novos" movimentos, assim como os "velhos"

trabalham por mais justiça, mais direitos e mais liberdade e são, ao mesmo tempo, movimentos que opõem categorias de pessoas a outras categorias, criando assim uma arena de conflitos sobre assuntos em que os ganhos de alguns são necessariamente combinados com as perdas de outros. ${ }^{26}$

Esse autor considera que "a classe não é um fato social, mas - além de ser uma construção teórica - é uma construção social". ${ }^{27}$. Para ele, "os movimentos sociais também criam relações de classe". Nessa perspectiva, chama a atenção para o papel das classes médias, defendendo a tese de que, com a emergência dos novos movimentos sociais, elas se tornaram, pela primeira vez, um elemento constitutivo de uma emergente nova estrutura de classes, baseada não no controle dos meios de exploração, mas sim dos meios de existência social identitários. ${ }^{28}$

Outros autores têm chamado ainda a atenção para as novidades que os movimentos contemporâneos trazem em termos de sua base social. Cefaï, por exemplo, argumenta que

\footnotetext{
${ }^{24}$ Ibidem, p. 168.

${ }^{25}$ Ibidem, p. 160.

${ }^{26}$ EDER, Klaus. A nova política de classes. Bauru, SP: Edusc, 2002, p. 259.

27 Ibidem, p. 283.

${ }^{28}$ Esse aspecto é ressaltado na apresentação de Brasílio Sallum Jr. à edição em português do livro de Eder, utilizada neste artigo.
} 
A questão social tornou-se o lugar central das contradições do novo mundo que emerge. Frequentemente, estabelecendo um paralelo com o século XIX, os "excluídos" tomam o lugar dos "proletários" e a sua integração no espaço da cidadania adquire o mesmo alcance universal que a emancipação da classe operária tinha outrora. $^{29}$

Essa parece ser uma questão universal. As crises sistêmicas, o desemprego, mas também a incorporação de novos territórios à lógica da reprodução capitalista vem sendo acompanhada pela resistência, cada vez mais organizada, dos que são afetados por esse processo. A novidade é que ela se dá por meio da afirmação de identidades étnicas e culturais que em algumas circunstâncias, como temos visto recentemente na América Latina, articula-se com um discurso classista, em defesa, por exemplo, do campesinato e de modos de vida que estão sendo ameaçados pela expansão capitalista.

\section{A FORMAÇÃO DO ATOR COLETIVO}

Uma das principais contribuições das teorias dos "novos movimentos sociais" foi, sem dúvida, colocar em questão a essencialidade do ator. Essa nova forma de olhar traz para o centro da reflexão sobre as lutas coletivas a necessidade de indagar sobre como é possível a constituição de um grupo mobilizado, com reivindicações e formas de ação próprias. Como já visto no item anterior, trata-se de outra maneira de perguntar e, por meio dela, o que era um dado torna-se o real objeto de investigação.

Cabe, pois, pensar sobre as ferramentas analíticas que nos permitam responder a essa questão crucial. Diversos autores têm enfatizado a necessidade de observar o crescente entrelaçamento das ações coletivas com questões relacionadas à vida cotidiana, à experiência individual, e tentar levar a análise para além das organizações políticas que se substancializam como a expressão visível dos conflitos.

Pioneiros nessa abordagem são os já citados trabalhos de Thompson, que recusou, em seu estudo sobre a sociedade inglesa do século XVIII e início do XIX, a equação simples que levava a entender a formação da classe operária como produto da Revolução Industrial. Em volumoso e detalhado estudo, o autor mostra que o operário que emerge no início do século XIX é uma categoria marcada por suas experiências anteriores, sua cultura, determinadas tradições dissidentes e libertárias, enraizadas na história inglesa. ${ }^{30}$ Segundo ele:

o fazer-se da classe operária é um fato tanto da história política e cultural quanto da econômica. Ela não foi gerada espontaneamente pelo sistema fabril. Nem devemos imaginar alguma força exterior - a "revolução industrial" - atuando sobre algum material bruto, indiferenciado e indefinível da humanidade [...] As mutáveis relações de produção e as condições de trabalho mutável da Revolução Industrial

\footnotetext{
${ }^{29}$ CEFAï, Daniel. Os novos movimentos de protesto em França. A articulação de novas arenas públicas. In: Revista Crítica de Ciências Sociais, 72, Lisboa, 2005, p. 150.

${ }^{30}$ THOMPSON, A formação..., op. cit.
} 
não foram impostas sobre um material bruto, mas sobre ingleses livres - livres como Paine os legou ou como os metodistas os moldaram.... ${ }^{31}$

Uma preocupação central do autor é mostrar a singularidade dessa classe operária, que se forma num contexto particular, radicalmente diferente do francês, por exemplo.

Em direção semelhante, Barrington Moore Jr. propõe-se a fazer um estudo da "indignação moral", buscando entender "as condições sociais e históricas sob as quais a indignação moral vem à tona". ${ }^{32}$ Para esse autor, a ira ocorre quando alguns princípios de reciprocidade e do que é considerado justo em cada sociedade é violado e chama a atenção para o fato de que cabe indagar sobre "o que precisa ocorrer aos seres humanos, a fim de fazê-los submissos à opressão e à degradação". ${ }^{33}$ Na conclusão de seu livro afirma que

as pessoas tendem a conferir legitimidade a qualquer coisa que seja, ou pareça ser, inevitável, não importa quão dolorosa. Caso contrário, a dor poderia ser intolerável. A conquista desde sentido de inevitabilidade é essencial para o desenvolvimento da indignação moral politicamente efetiva. Para isso acontecer, as pessoas têm de perceber e definir sua situação como consequência da injustiça humana: uma situação que não necessitam, não podem e não devem suportar". ${ }^{34}$

Essa perspectiva aproxima-se bastante daquela defendida por diversos estudiosos contemporâneos de movimentos sociais, que se preocupam com os processos que formam o ator coletivo. Para eles, assim como em Thompson e em Moore Jr., a recuperação das formas pelas quais as pessoas comuns vivenciam perdas, ofensas, bem como a maneira como elas enquadram essas experiências e lhes dão significados são fundamentais para entender como é possível a constituição de um ator coletivo, mas também para perceber em que situações produzem-se a conformidade e a passividade. Ganha centralidade o entendimento dos universos de sentido que se geram e a maneira como são vivenciados pelos atores.

A preocupação com a análise das formas como os atores percebem suas condições e reagem a elas está presente em várias vertentes analíticas das Ciências Sociais. $\mathrm{Na}$ sociologia americana, ela aparece como uma reação crítica ao racionalismo da teoria da mobilização de recursos e encontra seu principal porta-voz em David Snow que, por sua vez, inspira-se fortemente na frame analysis de Goffman. ${ }^{35}$ Trata-se, para ele, de dar relevo à forma como os atores sociais constituem/produzem sentidos e o lugar do conjunto de crenças e significados orientados para ação que inspiram e legitimam as atividades e as campanhas das "organizações de movimentos sociais".

\footnotetext{
${ }^{31}$ Ibidem, v. 2, p. 18.

${ }^{32}$ MOORE JR., Barrington. Injustiça. As bases sociais da obediência e da revolta. São Paulo: Brasiliense, 1987, p. 9.

33 Ibidem, p. 81.

34 Ibidem, p. 622.

${ }^{35}$ SNOW, David. Analyse de cadres et mouvements sociaux. In: CEFAï, Daniel e TROM, Danny (eds.). Les formes de l'action collective. Mobilisations dans des arènes publiques. Paris: École des Hautes Études en Sciences Sociales, 2001.
} 
Snow e Byrd (2010) chamam a atenção para o fato de que o uso da noção de framing $^{36}$ relaciona-se com o trabalho de significação, que é uma das atividades que as lideranças dos movimentos sociais e seus círculos próximos realizam regularmente, e deriva da necessidade de explicar o recrutamento e a participação em termos que não se reduzam à dimensão psicossocial. ${ }^{37}$ De acordo com Snow,

uma das funções dos movimentos sociais, particularmente dos que emergem num ciclo de protesto, é fornecer os enquadramentos alternativos ao que parecia derivar antes da má sorte ou da fatalidade, transformando-o em injustiça social ou em transgressão moral que convida à ação. ${ }^{38}$

O autor chama ainda a atenção para o fato de que

Os frames de ação coletiva podem proporcionar uma função interpretativa, focalizando, articulando e produzindo significados para atrair seguidores, transformar expectadores em apoiadores, extrair concessões dos alvos e desmobilizar antagonistas. ${ }^{39}$

Mas esses enquadramentos se enraízam num contexto cultural mais amplo, que os limita e constrange. Dessa forma, ainda segundo Snow, a frame perspective contém um elemento construcionista e um elemento estruturalista. Os enquadramentos culturais são dotados de grande variabilidade e a sua pertinência em situações de ação coletiva é tanto mais aberta quanto mais forem flexíveis. De acordo com o autor, o crucial do processo de enquadramento se situa nos processos conjuntos de articulação e de ampliação mais do que na unidade temática. ${ }^{40}$ Ele chama ainda atenção para a relação entre o processo de enquadramento e ideologias: estas constituem um estoque de recursos culturais do qual se podem tirar fontes para a construção dos quadros de ação coletiva, entendidos como "conjunto de crenças e significados emergentes que articulam as ideologias de forma inovadora e ampliando alguns aspectos". Nessa perspectiva,

os framings especificam a maneira pelas quais as reivindicações são produzidas, sustentadas e também contestadas e alteradas. Eles não remetem, pois, a entidades cognitivas, inseridas em sistemas de ideias coerentes e fechados. Sua essência sociológica consiste na interação social situada. ${ }^{41}$

A análise de framings conquistou um lugar importante na reflexão sobre os movimentos sociais, mas conforme Cefaï, acabou se afastando do sentido original da noção goffmaniana, reduzindo-a a um "repertório de recursos cognitivos, no qual os líderes de

\footnotetext{
${ }^{36}$ O termo é de difícil tradução em português e, para evitar perda de sentido, preferimos mantê-lo, em algumas passagens, em inglês. Em francês, os autores optam por "analyse de cadres".

37 SNOW, David; BYRD, Scott. Ideology, frame process and Islamic terrorist movement. In: MCADAM, Doug e SNOW, David. Reading on Social Movements. New York/Oxford: Oxford University Press, 2010.

${ }^{38}$ SNOW, Analyse de cadres..., op. cit., p. 35.

${ }^{39}$ SNOW BYRD, op. cit., p. 323.

${ }^{40}$ SNOW, Analyse de cadres... , op. cit.

${ }^{41}$ Ibidem, p. 39
} 
organizações vão vasculhar para montar estratégias de comunicação no jogo de suas alianças e oposições". ${ }^{42}$ Inspirado na tradição pragmatista, o autor preocupa-se, antes de tudo, com o conjunto das atividades que geram os enquadramentos. Procura, assim, recuperar os pressupostos interacionistas e captar os procedimentos de organização das experiências e atividades de descrição e interpretação disponíveis, criando o que ele chama de arenas públicas, nas quais ganha relevo o ator, mas também sua "audiência". A atenção volta-se, pois, para o esforço de captar como a experiência do mundo é formatada pelo "público". Para ele,

quando "indivíduos" se fazem "consumidores", "habitantes" ou "cidadãos", "mulheres", "desempregados" ou "imigrantes ilegais", por meio de suas denúncias e reivindicações, devem prestar contas (account) do que fazem, de por que o fazem e em vista do que o fazem. Certo número de ativistas trabalhou na constituição de uma linguagem comum, na enunciação de repertórios de identidade coletiva e na confecção de modos de engajamento público. ${ }^{43}$

Exemplificando seu argumento com a ação das mulheres, afirma que a tarefa das primeiras feministas foi

descobrir pontos comuns à situação das mulheres, conferir a disputas privadas um alcance público e converter mal-estares pessoais em causas coletivas. As ativistas que vêm em seguida não inventam abruptamente os papéis que desempenham, mas habitam universos de sentidos que lhes são legados, reorganizando-os em favor dos novos desafios que se apresentam. ${ }^{44}$

A ideia central defendida por Cefaï é que a ação coletiva se organiza organizando também seus ambientes. As experiências coletivas são marcadas por emoções: ódio, sentimento de injustiça, de paixão. Na percepção do autor, não se trata de um traço a mais, mas de enfatizar que as emoções são constitutivas da experiência. A ação coletiva está no agir, mas também no sofrer e no compartilhar. A perspectiva de valorização da pragmática dos regimes de ação, perspectiva defendida pelo autor, é uma incitação a desenvolver o esforço de descrever e analisar, em situação, a grande mistura de lógicas de racionalidade e de legitimidade que se imbricam nos cursos de ação, e de decifrar os modos de organização da experiência de atores e expectadores. ${ }^{45}$

$\mathrm{Na}$ busca do entendimento sobre como se forma o ator, uma das questões-chave é, pois, perceber como as pessoas transformam-se de expectadoras em participantes, o que envolve a construção de um vocabulário de motivos que possa ser partilhado por elas. Evidentemente, tal abordagem remete a uma perspectiva etnográfica de análise, capaz de captar as significações e re-significações que compõem o processo de constituição do ator coletivo.

\footnotetext{
${ }^{42}$ CEFAï, Como nos mobilizamos..., op. cit., p. 25-26.

43 Ibidem, p. 27.

44 Ibidem.

${ }^{45}$ Ibidem, p. 23.
} 


\section{CONTEXTOS DE AÇÃO, MOBILIZAÇÃO E A DIMENSÃO ORGANIZATIVA}

Um dos campos de pesquisa bastante fértil sobre movimentos sociais, pelo menos em termos de quantidade de trabalhos produzidos, tem sido aquele que procura partir da organização, aspecto mais imediatamente visível das mobilizações e das formas e razões de agir. A reflexão sobre esse tema difundiu-se nos Estados Unidos, em especial, por meio da chamada "teoria da mobilização de recursos", nos anos 1970. Bastante influenciada pela perspectiva de análise fundada na racionalidade do ator, em especial em Olson, sua ênfase centrou-se na capacidade de se apropriar de bens disponíveis, transformando-os em recursos para as mobilizações e organização. Nesse caso, a organização torna-se o objeto relevante para a análise, como o elemento que estrutura um grupo e mobiliza recursos em seu favor, tornando as mobilizações possíveis, atraindo adeptos e sendo capaz de gerar demandas. De acordo com Neveu, sob essa abordagem, as organizações são percebidas instâncias estratégicas nas quais esperanças difusas se fixam em reivindicações formalizadas e os recursos para ação são centralizados. ${ }^{46}$

Para que um movimento sobreviva, é importante que crie uma estrutura organizativa capaz de sustentar a ação coletiva. Ela pode nascer das oportunidades em torno, mas seu poder é delineado por suas próprias ações. É a organização formal que fala pelo movimento, que, crescentemente dita, seu curso, conteúdo e consequências da luta. Nessa perspectiva, as oportunidades políticas e o processo contextual são entendidos também como produto da dinâmica organizacional. ${ }^{47}$ Para os autores dessa corrente, os movimentos sociais podem ser entendidos como "empreendedores coletivos", capazes de se apropriar de oportunidades políticas e, assim, levar adiante seus objetivos. ${ }^{48}$

Sob essa perspectiva, as organizações são apreendidas pela sua capacidade de mobilização. Ao longo do debate que se desenvolveu acerca dessas teorias, novas variáveis foram acrescentadas, potencializando sua capacidade analítica e chamando a atenção para aspectos até então pouco considerados. Diversas críticas feitas conduziram a um alargamento dos elementos a ser considerados, incluindo os laços internos dos grupos, as redes de solidariedade, a formação de identidades como elementos-chave para o entendimento das "organizações de movimentos sociais", como muitos autores preferem falar.

\footnotetext{
${ }^{46}$ NEVEU, Eric. Sociologie des mouvements sociaux. Paris: La Découverte, 2005.

47 MCADAM, Doug; MCCARTHY, John e ZALD, Mayer. Comparative perspectives on social movements. Cambridge: Cambridge University Press, 1996.

${ }^{48}$ Sidney Tarrow, autor que tem se destacado nessa abordagem, considera as oportunidades como dimensões consistentes do ambiente político que produzem incentivos às pessoas para levar adiante a ação coletiva, afetando suas expectativas de sucesso ou fracasso. Consistem no grau de abertura do sistema político, que definem níveis de receptividade às demandas coletivas; no nível de estabilidade das alianças políticas, que permitem aos movimentos sociais jogar de forma mais ou menos intensa com as alianças políticas existentes; nas forças de apoio em posição estratégica e na possibilidade de divisão das elites; na capacidade do sistema político de desenvolver políticas públicas que atendam, em alguma medida, as demandas dos movimentos sociais. O autor também chama a atenção para o fato de que, se as oportunidades delimitam as possibilidades de ação de uma organização, os movimentos, pelas suas próprias ações, também criam oportunidades. Ver: TARROW, Sidney. O poder em movimento. Movimentos sociais e confronto político. Petrópolis: Vozes, 2009.
} 
Esse tipo de abordagem da dimensão organizativa teve o mérito de juntar o que algumas concepções anteriores separavam: organização e movimento, como se um não supusesse o outro, como se, sem organização, fossem possíveis mobilizações e a transformação de demandas difusas numa pauta de reivindicações e como se a organização destruísse o caráter fluido do movimento. No entanto, sofreu uma série de críticas: sem negar a importância das organizações na mobilização política e sua capacidade de produzir e organizar determinados consensos, trata-se de alertar para o perigo de isolá-las do mundo social em que emergem e que lhes fornece as próprias condições de existência e, muitas vezes, modos de operar. Melhor dizendo, o risco é transformar em explicação algo que tem que ser explicado.

Cefaï, por exemplo, chama a atenção para uma colonização das teorias da mobilização de recursos e das oportunidades políticas pela retórica da economia, do empreendimento e do empreendedor, da estratégia de rentabilização de interesses predeterminados e de capitais disponíveis. Para ele, trata-se de se indagar sobre o fato de que os atores "são confrontados a mundos, dos quais provam a realidade e a justiça em relação a suas maneiras de se engajar, são submetidos a coerções ecológicas fortes, mesmo dispondo de uma margem de manobra que lhes confere alguma liberdade". ${ }^{49}$ Segundo esse autor, trata-se, antes de tudo, de acompanhar a experiência e a perspectiva dos atores e de formação do "público" que, mais do que coagido por estruturas de oportunidades políticas, é capaz de redefinir o horizonte de possíveis. Nessa perspectiva, as fronteiras do político se alargam e o próprio sentido do poder muda: não é entendido somente como relação de dominação e de subordinação, nem de normalização e de resistência, mas também percebido como possibilidade, do lado do Estado, de instituição de capacidades e de direitos, e, do lado do público, como possibilidade de agir em acordo. ${ }^{50}$ Suas postulações vão no sentido de entender as organizações como reagrupamentos, mais ou menos fluidos, em torno de situações problemáticas a serem resolvidas, que põem em jogo uma "experiência criadora". ${ }^{11}$ As organizações passam a ser compreendidas, sob essa ótica, como nós de "redes de interações informais entre uma pluralidade de indivíduos, de grupos ou associações, envolvidos em um conflito cultural ou político, e partilhando uma identidade coletiva". ${ }^{52}$ Trata-se de redes preexistentes e que são fundamentais para pensar a forma como se agencia a ação.

\footnotetext{
${ }^{49}$ CEFAï, Como nos mobilizamos..., op. cit., p. 15.

${ }^{50}$ Ibidem, p. 16-17.

${ }^{51}$ CEFAï, op. cit., p. 19

52 Ibidem, p. 19. Para desenvolver seu argumento, Cefaï cita DIANI, Mario. The concept of social movement. Sociological Review, n. 40, 1992, p. 13.
} 


\section{A CONTINUIDADE DAS AÇÕES NO TEMPO E NO ESPAÇO: REPERTÓRIOS DE AÇÃO}

As análises de movimentos sociais tendem a recortar um ou outro tipo de movimento ou evento para análise em profundidade, privilegiando, pois, os "estudos de caso". No entanto, alguns autores se voltaram para uma perspectiva de mais longo prazo, tendo em vista buscar padrões de comportamento que se repetem ao longo do tempo, bem como perspectivas comparativas. O nome sempre ligado a esse tipo de abordagem é o de Charles Tilly, que fundou a noção de repertório de ação coletiva, entendido como sequências regradas de ações, marcadas por uma complexa interdependência e próprias a um tempo. 0 repertório é sempre peculiar a uma época e marcado por uma determinada relação entre protesto e poderes públicos. Em uma de suas obras mais conhecidas, o autor apresenta um repertório que chama de "antigo", que marcou as ações coletivas na Europa até o final do século XVIII, e que é caracterizado pelo localismo, pelos motins de subsistência e apropriação das colheitas; invasões coletivas de terrenos proibidos; destruição de barreiras de pedágio; ataques às máquinas, expulsões de funcionários encarregados da cobrança de impostos e de pessoas consideradas estranhas e alheias à comunidade; incêndios provocados; destruição e saque de casas particulares; representação de processos judiciais populares etc. ${ }^{53}$ Trata-se de um repertório de características eminentemente locais. As mudanças econômicas e políticas que se produziram nos países ocidentais ao largo do século XIX levaram à substituição do repertório tradicional por outro, de caráter nacional. As ações passaram a ser dirigidas contra as autoridades nacionais, implicavam em enfrentamento radical com as autoridades, envolviam ações contra os patrões (greves, por exemplo), muitas vezes, tomavam a forma de ações relacionadas a processos eleitorais, os participantes articulavam-se em associações (como os sindicatos, por exemplo).

Na perspectiva de Tilly, a mudança de um repertório para outro relaciona-se com o desenvolvimento do capitalismo, a urbanização e a constituição dos estados nacionais. Nesse processo, os interesses das pessoas comuns ultrapassaram a esfera local e suas questões adquiriram perfil nacional. Para que essa mudança ocorresse, foi decisivo o reconhecimento dos direitos de reunião e associação, a ampliação do sistema eleitoral e das comunicações. Segundo Tilly, as formas de ação que compunham o que ele chama de "novo repertório" tinham um caráter cosmopolita, modular e autônomo:

Elas eram cosmopolitas ao referir-se com frequência a interesses e questões que diziam respeito a muitas localidades ou afetavam centros de poder cujas ações atingiam muitas outras. Eram modulares por serem facilmente transferíveis de um local ou circunstância para outros... Eram autônomas ao começarem dos próprios reclamantes e estabelecer contato direto entre esses e os centros de poder nacionalmente significativos. ${ }^{54}$

\footnotetext{
${ }^{53}$ TILLY, From mobilization to revolution..., op. cit.

54 . Popular contention in Britain, 1758-1834. Cambridge, Massachussets: Harvard University Press, 1995, apud TARROW, Poder em movimento, op. cit., p. 52
} 
Como apontam alguns autores, com o passar do tempo, o repertório se rotiniza e torna-se parte da política convencional:

A greve torna-se uma instituição de barganha coletiva; a demonstração foi coberta por um conjunto de leis que tanto a regulavam como a distinguiam de atividades criminosas; e os movimentos pacíficos e a ocupação de edifícios foram tratados com mais indulgência do que a delinquência comum. ${ }^{55}$

Não seria possível, no âmbito deste artigo, explorar as reflexões de Tilly e suas modulações ao longo do tempo. Em mais de duas dezenas de livros ele, foi amadurecendo seu pensamento, sempre na direção de entender as transformações de longa duração e a busca de mecanismos causais comuns, de menor escala, que operam em diferentes tempos e locais. Num de seus estudos mais recentes e mais conhecidos, escrito em colaboração Sidney Tarrow e Douglas McAdam, amplia a noção de repertório, entendido como um conjunto limitado de rotinas que são aprendidas, compartilhadas e postas em ação por meio de um processo relativamente deliberado de escolha. ${ }^{56}$ Nesse trabalho, os autores buscam enfatizar os mecanismos dinâmicos que colocam em interação variáveis como oportunidades políticas, peso da mudança social, estruturas de mobilização, ações transgressoras e quadros explicativos (framings). ${ }^{57}$ Trata-se de explicar não as oportunidades políticas em si, mas o que permite que uma oportunidade seja percebida como tal. É acentuada a interação social presente nos conflitos e colocada no centro da reflexão a busca do entendimento de como a interação constrói o ator. Ou seja, buscam recuperar o lugar da agência. Ao mesmo tempo, refletem sobre o tema da escala, que implica em mudança no número e no nível das ações: a ampliação da escala traz novos participantes e novos significados. Outra variável aparece como central na explicação: o regime político, uma vez que cada regime define as oportunidades políticas, na medida em que "ameaças e oportunidades mudam com a fragmentação ou a concentração de poder, a instabilidade dos alinhamentos políticos, a presença de aliados potenciais". ${ }^{8}$ Assim, a análise se centra fundamentalmente na relação movimentos sociais e Estado, uma relação compreendida como eminentemente conflitiva.

Se a noção de repertório assinala que nem os indivíduos nem os grupos podem construir sequências de ação buscando maximizar seus ganhos em cada ato, e que a ação é cercada por constrangimentos estruturais que delimitam as possibilidades de agir, fornece, no entanto, poucas possibilidades de explicar como os indivíduos escolhem tal ou qual caminho. Sobre esse aspecto, Fillieule chama a atenção sobre a necessidade de levar em

\footnotetext{
${ }^{55}$ TARROW, op. cit., p. 65.

56 MCADAM, Doug, TARROW, Sidney e TILLY, Charles. Dynamics of contention. Cambridge: Cambridge University Press, 2001.

${ }^{57}$ Para os autores, mecanismos são eventos delimitados que alteram as relações entre determinados tipos de elementos, de forma idêntica ou muito próxima numa variedade de situações. Processos são sequências regulares desses mecanismos, que produzem transformações similares (geralmente mais complexas e contingentes) desses elementos. Ver: MCADAM, TARROW, e TILLY, op. cit.

${ }^{58}$ TILLY, Charles e TARROW, Sidney. Politique(s) du conflict. De la grève à la révolution. Paris: Presses de SciencesPo., 2008, p. 107
} 
conta mais seriamente a cultura, como "filtro por meio do qual essas oportunidades objetivas são percebidas de maneira variável segundo os agentes". ${ }^{59}$ Trata-se, segundo ele, de considerar as performances coletivas e as interações que nelas ocorrem, considerando-as como momentos de construção e/ou reforço de solidariedades e identidades coletivas; como rituais que contribuem para a formação da adesão e da unanimidade; como formas de socialização política. Acrescentaríamos que elas são um momento importante também da construção de alianças e de delimitação de adversários, para além dos poderes públicos (que são o foco principal das reflexões de Tilly).

\section{ESPAÇO PÚBLICO E INTERAÇÕES SOCIEDADE E ESTADO}

Um dos campos férteis de reflexão e pesquisa sobre movimentos sociais é a relação entre eles e a sociedade de onde brotam. Uma das alternativas para pensar essa relação é oferecida por Jean Cohen e Andrew Arato, que, num estudo clássico e referencial, analisam os movimentos sociais como uma dimensão normal, ainda que extra-institucional, da ação política nas sociedades civis modernas. A obra desses autores marcou profundamente os debates dos anos 1990 e tendeu a valorizar a sociedade civil, esfera na qual os movimentos sociais agem. ${ }^{60}$

Partindo das concepções de Habermas, Cohen e Arato entendem que, apesar desse autor reconhecer que as lutas contemporâneas se localizam em torno das dimensões da reprodução cultural, integração social e socialização, ele não as vincula com o lado positivo das instituições dentro da sociedade civil e da sociedade política. Segundo eles, a tendência de Habermas, pela separação rígida que faz entre sistema e mundo da vida, é ver os subsistemas como fechados. Essa percepção faz com que ele só consiga perceber o caráter defensivo dos movimentos sociais contemporâneos e não suas estratégias ofensivas, dirigidas à sociedade política e econômica, mas também a uma política de influência voltada aos que se encontram dentro do sistema político (e talvez econômico) e a projetos autolimitadores de reforma institucional.

Para Cohen e Arato, os movimentos sociais são, antes de tudo, lutas que buscam democratizar a sociedade civil para protegê-la da "colonização" econômica e política e que tentam exercer influência sobre a sociedade política. O seu êxito deve, assim, ser percebido não em termos da obtenção de certas metas substantivas ou da perpetuação do movimento, mas antes, em termos da democratização de valores, normas e instituições que, em última instância, estão arraigados na cultura política. Nessa perspectiva, os chamados "novos" movimentos sociais não são somente uma política institucional anticultural: geram novas solidariedades, alteram a estrutura associativa da sociedade civil e criam uma pluralidade de novos espaços públicos, uma vez que ampliam e revitalizam espaços que já estão

\footnotetext{
59 FILLIEULE, Olivier. Tombeau pour Charles Tilly. Répertoires, performances et stratégies d'action. In : FILLIEULE, Olivier ; AGRIKOLIANSKY, Éric e SOMMIER, Isabelle (eds.). Penser les mouvements sociaux. Conflicts sociaux et contetations dans les sociétés contemporaines. Paris: La Découverte, 2010, p. 95.

${ }^{60}$ COHEN, Jean L. e ARATO, Andrew. Sociedad civil y teoria politica. México: Fondo de Cultura Economica, 2000. A edição original, em inglês, é de 1992.
} 
institucionalizados, o que supõe desafiar os papéis mediadores entre sistema e mundo da vida. Propondo-se a entender o conceito habermasiano de mundo da vida como a articulação institucional de uma sociedade civil garantida por direitos, querem analisar como os movimentos sociais operam em ambos os lados da divisão entre mundo da vida/sistema. Para tanto, introduzem um conceito de poder mais amplo que o de Habermas (que tende a restringi-lo à dimensão burocrática): entendem-no como transferência de seletividade, vista como habilidade para determinar o que se pode fazer ou dizer e chamam a atenção para um conjunto de reformas que não criam clientes isolados de uma burocracia estatal, mas dá aos indivíduos o poder de atuar coletivamente, desenvolver novas solidariedades e obter um maior equilíbrio das relações de poder, porque estão dirigidas a uma área que já está formalmente organizada. Discutem o tema dos direitos e do direito, mostrando que a juridicização da vida implementa relações verticais, mas também horizontais: uma vez institucionalizados, os direitos tornam-se ponto de apoio e catalizadores de outras lutas por direitos.

Por um caminho diverso, Cefaï aponta que a reivindicação por uma democracia deliberativa e participativa é cada vez mais forte, em oposição ao controle exercido por aparelhos burocráticos. Segundo ele, se a "política" não invade a totalidade da vida privada, ela não representa um domínio circunscrito, alheado do resto da vida quotidiana. ${ }^{61}$ Os movimentos sociais são, então, percebidos como catalisadores e aceleradores da formação dessa "cultura pública" e como contraponto do que se costumava chamar transformações de moralidade, usos e costumes. ${ }^{62}$

Esse tipo de reflexão sugere que se avance nas relações entre Estado e movimentos sociais. Se grande parte da literatura (e a própria percepção dos movimentos sobre suas concepções e práticas) sugere uma radical separação e distinção entre movimentos sociais e Estado, vendo-os como opositores, é importante ter em conta como essas relações podem se dar no fluxo dos conflitos e sua complexidade.

Rebeca Abers e Marisa Von Bulow chamam a atenção para esse aspecto, tendo como suporte algumas inquietações surgidas com base na análise da situação brasileira. Partindo do pressuposto de que os movimentos sociais têm lutado tanto para transformar comportamentos sociais como para influenciar políticas públicas, alertam para uma questão pouco estudada, que é a participação direta no interior das instituições estatais:

Como parte desses esforços, muitas vezes [os movimentos sociais] se mobilizam em prol de mudanças nos processos de tomada de decisão estatal, demandando a inclusão da sociedade civil em novos espaços participativos. Essa demanda implica não somente na criação de espaços de diálogo entre atores da sociedade civil e do governo, mas da maior presença de ativistas de movimentos sociais dentro do próprio Estado. ${ }^{63}$

\footnotetext{
${ }^{61}$ CEFAI, Os novos movimentos... op. cit.

62 . Como nos mobilizamos..., op. cit., p. 36.

${ }_{63}$ ABERS, Rebeca e VON BULOW, Marisa. Movimentos sociais na teoria e na prática: como estudar o ativismo através da fronteira entre Estado e sociedade? Sociologias, Porto Alegre, ano 13, n. 28, set./dez., 2011 , p. 65.
} 
As autoras estão particularmente interessadas nos riscos que essa prática envolve e no fato de que ela exige dos ativistas a defesa de interesses que não seriam necessariamente defendidos anteriormente. Mas, segundo elas, isso não significa necessariamente cooptação: esses atores buscam transformar o Estado ao tentar, por exemplo, promover políticas públicas socialmente justas ou criar arenas nas quais grupos da sociedade civil possam participar, o que traz questões interessantes para a análise: trata-se de estar atento à possibilidade de, em algumas situações, os movimentos sociais buscarem alcançar seus objetivos trabalhando dentro do aparato estatal. Aprofundando seu argumento, sugerem ainda que alguns movimentos sociais parecem ter sido até mesmo criados a partir de alianças entre indivíduos dentro e fora do Estado. Fornecem os exemplos da reforma do sistema de saúde nos anos 1990 e as ações do Ministério Público, fundamentais "para transformar demandas da sociedade civil em demandas legais, com poder para mobilizar o sistema judiciário e assim pressionar os Poderes Executivo e Legislativo". ${ }^{64}$ Para essas autoras, o grande desafio é "mapear e analisar as redes que conectam atores de movimentos sociais com atores estatais". ${ }^{65}$

O outro lugar privilegiado para se pensar essa relação é a esfera jurídica que, muitas vezes, tem ficado na obscuridade ou, pelo menos, é tratado como uma dimensão secundária da luta política. Agrikoliansky relaciona a pouca atenção que vem sendo dada à dimensão legal da luta política ao fato de que as abordagens dominantes de ação coletiva dão ênfase principalmente ao caráter não institucional das estratégias empregadas pelos que protestam. De acordo com ele, embora questões relacionadas ao direito sejam tratadas do ponto de vista das consequências das ações dos movimentos sociais, de seus efeitos sobre a legislação, ou das relações entre o Estado e os que protestam,

o direito como repertório de ação coletiva foi pouco tratado em si mesmo e de maneira sistemática pelas análises dos protestos. Evidentemente, a principal causa disso reside, sem dúvida, na própria definição do objeto "movimento social" pelos analistas do "processo político" ou da "contentious politics". ${ }^{66}$

Como aponta esse autor, "o direito, como linguagem e meio de ação, é potencialmente uma possante gramática para pensar as injustiças, construir reclamações e exprimir reivindicações" ${ }^{67}$ Como instrumento de mobilização das vítimas e de enquadramento da injustiça, as estratégias jurídicas constituem "um vetor da generalização das reivindicações que pode contribuir de maneira decisiva para o desenvolvimento de um movimento social" ${ }^{68}$ Assim, o espaço do Judiciário pode ser percebido como uma arena propícia à publicização e à mobilização de apoios.

\footnotetext{
${ }^{64}$ Ibidem, p. 70.

${ }^{65}$ Ibidem, p. 78.

${ }^{66}$ AGRIKOLIANSKY, Eric. Les usages protestataires du droit. In : FILLIEULE, AGRIKOLIANSKY e SOMMIER, op. cit., p. 226.

67 Ibidem, p. 225.

68 Ibidem, p. 230.
} 
É possível pensar a juridicização dos conflitos não só como uma forma de disputa de interpretação das leis, mas também como possibilidade de construção de uma retórica jurídica, baseada em princípios distintos que passa a conflitar e disputar espaços com a retórica estabelecida. Trata-se de buscar sair da armadilha de pensar a lei como dado e atentar para a dinâmica de continuidades e rupturas na prática da lei, suas possibilidades de reinterpretação e de constituição de novas percepções do Direito.

\section{FORMAS DE COMUNICAÇÃO E EXPANSÃO DOS MOVIMENTOS}

Partindo do pressuposto que a constituição de um grupo social faz parte de um processo complexo, que envolve múltiplas atividades, nem sempre visíveis, a literatura sobre o tema tem se preocupado em mapear e analisar os instrumentos que os grupos acionam para se fazer ver e representar, para construir sua imagem pública: manifestações, encontros (de abrangência diferenciada), congressos, marchas, atividades de formação etc. ${ }^{69}$ A esse conjunto de aspectos, agregamos as atividades de comunicação, com a produção de um material específico, que funciona como que um espelho da imagem que o grupo mobilizado busca construir, um caminho para chegar às "bases" e aos que potencialmente podem se incorporar tanto como "base", como quanto apoio, aliança etc. ${ }^{70}$ Os meios de comunicação também produzem uma imagem do outro, dos pontos de divergência no campo político, bem como de possíveis convergências.

Sob essa perspectiva, a formação de identidades políticas e organizações de representação é um processo carregado de historicidade, que implica múltiplos investimentos e afirmação de diferenças. Entender o processo de socialização do reconhecimento dos grupos em luta e de suas demandas é central. Embora a imprensa não seja o único espaço em que esse processo se dá, certamente é aquele que tem grande importância para garantir alguma continuidade de bandeiras e troca de experiências nos períodos de desmobilização. É por meio dela que se socializam valores, concepções e que se criam adesões. Ela é ainda um instrumento de difusão das "inovações culturais", que constituem, para alguns autores, o cerne da dimensão política dos movimentos sociais. ${ }^{71}$

Como lembra Natalie Zemon Davis, a palavra impressa, mais do que uma fonte de ideias e imagens, é mensageira de relações e afeta determinados ambientes. ${ }^{72}$ Essa propriedade é muito mais evidente quando se considera uma imprensa produzida por organizações que se colocam como porta-vozes de determinados segmentos que em seu lugar social, produzem modelos a serem seguidos, constroem e disputam visões de mundo. Segundo Tarrow, imprensa e organização caminham juntas na construção da controvérsia e

\footnotetext{
${ }^{69}$ Sobre esse aspecto, cf: THOMPSON, A formação da classe.... op. cit., ; BOURDIEU, o poder simbólico..., op. cit.; e CHAMPAGNE, Patrick. Formar a opinião. O novo jogo político. Petrópolis: Vozes, 1996.

${ }^{70}$ Sobre o conceito de "base", ver: SUAUD, Charles. Le mythe de la base: les états généraux du développement agricole et la production d'une parole paysanne". In: Actes de la recherche en Sciences Sociales, 52/53, 1984.

${ }^{71}$ A esse respeito, ver ALEXANDER, op. cit.; e MELUCCI, $A$ invenção..., op. cit.

72 DAVIS, Natalie Zemon. Culturas do povo. Rio de Janeiro: Paz e Terra, 1990.
} 
dão ao povo informações sobre como lidar com ela. ${ }^{73}$ Para ele, as fontes impressas e as associações difundem a ação coletiva para coalisões mais amplas e são fundamentais para a construção de um movimento social nacional, por meio da formação do que chama de "comunidades invisíveis". Por outro lado, a imprensa traz aos grupos notícias de outros lugares, eventos, experiências. A imprensa tem peso também na construção de laços entre grupos sociais distintos, fundamentais para a emergência de movimentos sociais de caráter nacional e internacional, na medida em que difunde o movimento para novos públicos e amplia a possibilidade de aumentar círculos de simpatizantes ou alianças.

$\mathrm{O}$ advento dos meios de comunicação de massa trouxe importantes efeitos para a política e construção da esfera pública. Como aponta Champagne, o jogo político concentrase, hoje, em torno da opinião pública em sua forma moderna. ${ }^{74}$ Num universo largamente controlado pelos meios de comunicação de massa, em especial, a televisão, que penetra todos os lares e assim tem um papel central na construção de opinião, a chamada "mídia popular" ou a mídia produzida pelas organizações ligadas aos trabalhadores assume múltiplos papéis: é nela que se trava um dos capítulos importantes da atividade política de construção do convencimento em torno de determinadas verdades, para onde se trazem notícias e interpretações que não encontram lugar nos meios de comunicação de massa.

Klandermans também chama a atenção para esse fenômeno. Segundo ele, se não examinamos o discurso dos meios de comunicação e se não investigamos como esse discurso muda ao longo do tempo, seremos incapazes de compreender a formação e ativação do potencial de mobilização dos movimentos sociais. ${ }^{75}$ Os meios de comunicação criados pelos movimentos têm um papel central no que o autor chama de "mobilização do consenso", uma questão de política simbólica e de construção social de significado. De acordo com ele,

situar as organizações de movimento social dentro de grupos integrados por setores que podem ser de apoio, antagonistas ou simplesmente indiferentes, nos permite obter uma imagem muito mais dinâmica dos movimentos sociais que a implícita nos enfoques anteriores, que analisavam os movimentos sociais como um fenômeno independente. ${ }^{76}$

Ainda segundo esse autor, é nesse terreno que se interpretam as injustiças, se definem os meios e as oportunidades para a ação, se identificam os oponentes, se definem as estratégias e se avaliam os resultados.

Nos últimos anos, além da imprensa escrita e de programas radiofônicos e televisivos, os movimentos têm se utilizado largamente de outros meios de comunicação, viabilizados pela internet. As mais significativas organizações hoje, tanto de caráter nacional como local, têm suas páginas na web, onde difundem conteúdos relacionados às suas

\footnotetext{
${ }^{73}$ TARROW, op. cit.

${ }^{74}$ CHAMPAGNE, op. cit.

${ }^{75}$ KLANDERMANS, Bert. La construcción social de la protesta y los campos pluriorganizativos. In Enrique Laraña e Joseph Gusfield. Los nuevos movimientos sociales. De la ideologia a la identidad. Madrid: Centro de Investigaciones Sociologicas, 1991, p. 187.

${ }^{76}$ Ibidem, p. 213.
} 
atividades, suas interpretações dos fatos e de notícias veiculados pela grande mídia. Da mesma forma, o correio eletrônico permite uma comunicação rápida e de grande alcance, eliminando as barreiras das distâncias físicas. ${ }^{77}$ Assim é possível afirmar que, atualmente, as novas gerações de ativistas estão todas conectadas em rede, e a publicidade das causas, dos debates e das lutas vem se deslocando do jornal impresso, rádio e televisão para as arenas eletrônicas. ${ }^{78}$ Cada vez mais, a internet tem um papel importante de articular militantes, atrair adesões, divulgar causas, convocar manifestações etc., permitindo que se indague sobre a possibilidade de pensar as ações por meios virtuais como inauguradoras de um novo repertório de ação, no sentido utilizado por Tilly.

\section{TRANSNACIONALIZAÇÃO DOS MOVIMENTOS SOCIAIS}

As questões levantadas ao longo deste artigo ganham novas dimensões quando se pensa no processo de crescente transnacionalização dos movimentos sociais, que coloca novos desafios teóricos e metodológicos para a compreensão dos movimentos sociais contemporâneos. Embora a dimensão internacional de diversas lutas sociais não se constitua em novidade, como demonstram o estudo de Perrot sobre a constituição do Primeiro de Maio como data simbólica para os trabalhadores ${ }^{79}$ ou a constituição das Internacionais Socialistas ainda no final do século XIX e início do $X X{ }^{80}$ o fato é que nos anos recentes, a transnacionalização dos movimentos sociais se intensificou. Como aponta Sidney Tarrow, ela foi facilitada pela comunicação eletrônica, que permite a rápida difusão de informações; pelo barateamento das viagens internacionais; pela difusão do inglês (que cada vez mais se torna a língua comum de comunicação) e pela expansão do "script" da modernidade. ${ }^{81}$

Esse processo tem provocado discussões sobre que relações se estabelecem entre o local e o global nesse novo quadro, bem como sobre o papel do Estado nas sociedades contemporâneas. Se, para muitos, o internacionalismo significa a fragilização e a perda de importância dos Estados nacionais, Tarrow adverte que ele não é uma força inexorável trabalhando contra o Estado, mas uma ampla rede de instituições, regimes, práticas e processos que incluem atores estatais e que penetram na política doméstica. Considera ainda que os que entram no ativismo transnacional estão constrangidos e, ao mesmo tempo, apoiados nas redes locais, ativam processos de transição entre os Estados e a política internacional e trazem para as suas regiões novas formas de ação e de compreensão das

\footnotetext{
77 Isso sem mencionar instrumentos outros como Facebook e Twitter, cujo potencial comunicativo e mobilizador na esfera da política começa a ser investigado.

${ }^{78}$ Esse é um tema que merece investigações mais cuidadosas, uma vez que, pelo menos no Brasil, além do uso de páginas na web, boletins eletrônicos e redes sociais diversas, grande parte das organizações populares ainda valorizam os jornais impressos como forma de comunicação com seus seguidores.

79 PERROT, Michelle. O primeiro de maio na França (1890): nascimento de um rito operário. In: . Os excluídos da história. Rio de Janeiro: Paz e Terra, 1988.

80 BRAGA, Flávia Vieira. Dos proletários unidos à globalização da esperança: um estudo sobre internacionalismos e a Via Campesina. São Paulo: Alameda Editorial, 2010.

${ }^{81}$ TARROW, Sidney. The new transnational activism. Cambridge: Cambridge University Press, 2005.
} 
questões domésticas e até mesmo novas identidades, que podem contribuir para a fusão de conflitos domésticos com os internacionais. Ou seja, não há dicotomia entre o local e o global. $^{82}$

Breno Bringel, que faz, em seus trabalhos mais recentes, um intenso diálogo com Tarrow, defende que somente pelo acompanhamento das múltiplas escalas, redes e dinâmicas de confronto "seremos capazes de observar que não há uma dicotomia entre o local e o global, que interagem continuamente", e que as escalas de ação dos movimentos sociais são "contingentes e construídas socialmente". ${ }^{83}$ Se nos detivermos só no olhar para o local, talvez percamos de vista a importância que ganham as alianças internacionais para dar voz, criar uma rede de proteção e denúncia às lutas locais. O grande desafio da pesquisa seria transitar nessa complexidade percebendo a dinâmica das redes que articulam esses diferentes pontos, mas que também podem promover estranhamento e ruptura a cada momento.

Quando nos voltamos para essas dimensões, não há como deixar de ficar atento ao fato de que o esforço de construção de uma agenda comum entre diferentes organizações, com culturas e histórias distintas, envolve sérias dificuldades na tradução de laços e as demandas locais para uma pauta mais genérica. Da mesma forma, há que se considerar que a circulação de ideias que esses encontros e trocas produzem pode significar importantes aquisições para os movimentos locais: questões particulares podem ser resignificadas em termos outros, que ultrapassam as fronteiras locais e, assim, se ampliar e, possivelmente, produzir novas tensões. Um exemplo sempre utilizado para exemplificar esse aspecto é a discussão em torno dos direitos humanos, que vem se tornando uma linguagem comum de tradução de demandas dos mais diferentes movimentos, mas que, ao mesmo tempo, em determinadas situações confronta-se com princípios de organização social e valores arraigados.

Alguns autores têm inclusive chamado a atenção para a constituição de uma esfera pública transnacional, entendida tanto como um espaço real como também elaborado no plano conceitual, no qual as organizações interagem, se contestam mutuamente e aprendem umas com as outras. Há que se considerar ainda que sua criação envolve uma ação à distância, o que implica que ela é assimétrica em termos de autoridade e de consumo, fato que a distancia do igualitarismo presumido na discussão da esfera pública. ${ }^{84}$

São temas em aberto, que mostram as possibilidades, mas também dificuldades com que se defrontam as pesquisas sobre movimentos sociais, para as quais se coloca, mais uma vez, o desafio de fazer dialogar o instrumental analítico disponível com as questões trazidas pelo mundo contemporâneo, bem como enfrentar a necessidade de um diálogo interdisciplinar. Acompanhar os atores pelos diferentes espaços onde transitam, perceber as

\footnotetext{
82 Ibidem.

83 BRINGEL, Breno. A busca de uma nova agenda de pesquisa sobre os movimentos sociais e o confronto político: diálogos com Sidney Tarrow. In: Política \& Sociedade, vol. 10. No. 8, abril/2011, p. 63.

${ }^{84}$ GUIDRY, John; KENNEDY, Michael e ZALD, Mayer. Globalizations and social movements. In: GUIDRY, John; KENNEY, Michael e ZALD, Mayer N. (eds.). Globalizations and social movements. Culture, power and the transnational public sphere. Michigan: The University of Michigan Press, 2000.
} 
diferentes relações que são construídas desde o local ao internacional, as mudanças que se operam nesses diferentes planos, todos eles indispensáveis para a análise, são os desafios a nós oferecidos. 